\title{
Comprehensive mutation detection of $B R C A 1 / 2$ genes reveals large genomic rearrangements contribute to hereditary breast and ovarian cancer in Chinese women
}

\author{
Wen-Ming Cao ${ }^{1+}$, Ya-Bing Zheng ${ }^{1 \dagger}$, Yun Gao ${ }^{2}$, Xiao-Wen Ding ${ }^{3}$, Yan Sun ${ }^{1}$, Yuan Huang ${ }^{1}$, Cai-Jin Lou', \\ Zhi-Wen Pan ${ }^{4}$, Guang Peng ${ }^{5}$ and Xiao-Jia Wang ${ }^{1 *}$
}

\begin{abstract}
Background: Mutated BRCA1/2 genes are associated with hereditary breast and ovarian cancer (HBOC). So far most of the identified BRCA1/2 pathogenic variants are single nucleotide variants (SNVs) or insertions/deletions (Indels). However, large genomic rearrangements (LGRs) such as copy number variants (CNVs) are also playing an important role in HBOC predisposition. Their frequency and spectrum have been well studied in western populations but remain largely unknown for Chinese population.

Methods: Peripheral blood samples were collected from 218 unrelated familial breast and/or ovarian cancer (FBOC) patients living in Eastern China. PCR-based Sanger sequencing and panel-based next-generation sequencing (NGS) were performed to detect pathogenic SNVs and Indels in BRCA1/2 genes. For the patients lacking small pathogenic variants, multiplex ligation dependent probe amplification (MLPA) assay was conducted to screen for LGRs.

Results: In total, we identified 44 samples (20.1\%) carrying small pathogenic variants (26 in BRCA1 and 18 in BRCA2, respectively). Among the rest of 174 samples, five were found carrying novel deleterious LGRs in BRCA1 which are exon5-7dup (1 patient), exon13-14dup (2 patients), and exon1-22del (2 patients). No LGR was found in BRCA2. Overall, LGRs accounted for $16.1 \%$ (5/31) of BRCA1 pathogenic variants, and were detected in 2.3\% (5/218) of all FBOC patients.,

Conclusions: LGR variants in BRCA1 gene play a significant role in Chinese HBOC patients. MLPA or other similar LGRdetecting methods should be recommended along with nucleotide sequencing as the initial screening approach for Chinese $\mathrm{HBOC}$ women.
\end{abstract}

Keywords: Chinese, Familial breast cancer, Familial ovarian cancer, BRCA1, BRCA2, Rearrangement

\section{Background}

According to National Central Cancer Registry of China, breast cancer ranks No.1 in cancer incidence and sixth in cancer-associated death for Chinese women, with over 250,000 newly diagnosed cases and 70,000 breast cancer-associated death in 2015 [1]. The average onset

\footnotetext{
* Correspondence: wxiaojia@yahoo.com

${ }^{\dagger}$ Wen-Ming Cao and Ya-Bing Zheng contributed equally to this work.

'Department of Medical Oncology, Zhejiang Cancer Hospital, 1 Banshan East Road, Hangzhou 310022, China

Full list of author information is available at the end of the article
}

age of breast cancer is $45-55$ years old for Chinese women, which is also younger than observed for Caucasian women [2]. While majority of breast cancer cases are sporadic, patients with familial history or other risk factors such as early onset age have been frequently observed in clinic, suggesting an important role of genetic factors in the disease development. Indeed, germline pathogenic variants in the two major breast cancer susceptibility genes $B R C A 1 / 2$ have been detected within Chinese patients [3-9].

(c) The Author(s). 2019 Open Access This article is distributed under the terms of the Creative Commons Attribution 4.0 International License (http://creativecommons.org/licenses/by/4.0/), which permits unrestricted use, distribution, and 
Studying $B R C A 1 / 2$ pathogenic variants requires accurate and comprehensive testing methods. Short-read DNA sequencing methods, including both Sanger and next-generation sequencing (NGS), are only capable of reliably detecting small variants such as single nucleotide variants (SNVs) or insertion/ deletion (Indels), but not suitable for detecting large genomic rearrangements (LGRs), which involve deletions or duplications of multiple exons [i.e. copy number variants (CNVs)]. Therefore, sequencing alone may lead to underestimated frequency of pathogenic variants. Southern blotting could be used to detect LGRs [10], but is labor intensive and generally low-throughput. SNP or CGH arrays can detect copy number variants but their unit cost is high and resolution is usually over hundreds of $\mathrm{Kb}$. Several multiplex PCR-based techniques have been recently developed to achieve higher processing and cost efficiency. For instance, multiplex ligation dependent probe amplification (MLPA) assay and multiplex amplicon quantification (MAQ) have been developed as fast and reproducible methods for $\mathrm{CNV}$ detection [11]. At the present, MLPA remains to be the most commonly used method for LGRs, and has detected 82.7 and 53\% LGRs in BRCA1 and BRCA2, respectively [12].

As of today BRCA1/2 LGR studies have been mostly conducted in western countries, showing different prevalence with ethnicity and geography. For example, there was no $B R C A 1 / 2$ LGR variants detected in Ashkenazi Jewish familial breast cancer patients [13, 14], but in non-Ashkenazi Jewish, the frequency of LGRs was $6 \%$ [14]. Very limited research has been conducted for Chinese, and only 12 BRCA1/2 LGRs have been so far reported. Those studies were conducted in Hong Kong [15], Singapore [16] and Malaysian [17]. The frequency and spectrum of $B R C A 1 / 2$ LGRs in familial breast cancer patients from China mainland remain largely unknown.

\section{Methods}

\section{Patient subjects}

A total of 218 unrelated familial breast cancer patients were enrolled into this study between 2008 and 2017 . All patients were diagnosed in Zhejiang Cancer Hospital in Eastern China and had a family history of at least one first- or second-degree relatives affected with breast cancer and/or ovarian cancer, regardless of age. Peripheral blood samples from the patients were collected in EDTA tubes and stored at $-80^{\circ} \mathrm{C}$. SNVs and Indels variants of $B R C A 1 / 2$ were firstly determined for all patients using sequencing methods (PCR-based Sanger sequencing and panel-based NGS). The patients with negative sequencing finding were further screened for LGRs by MLPA. The written informed consents were obtained from all participating patients prior to clinical data and peripheral blood collection. This study was approved by the
Research and Ethical Committee of Zhejiang Cancer Hospital, China. All experiments were performed in accordance with the approved guidelines.

\section{DNA extraction}

Genomic DNA was extracted from peripheral blood samples using QIAamp DNA Blood Mini kit (Qiagen, Hilden, Germany) by following the manufacture's manual. DNA purity and concentration were measured by NanoDrop 2000 Spectrophotometer and Qubit 3.0 (Thermo Fisher Scientific, Waltham, USA), and DNA integrity was determined by agrose gel electrophoresis.

\section{Nucleotide sequencing}

The present study used both PCR-based Sanger sequencing and panel-based NGS to interrogate small nucleotide variants including SNVs and Indels. In the first phase of the project, Sanger sequencing was performed on 133 unrelated FBOC cases using a total of 72 pairs of oligos to cover all coding exons and intron-exon boundaries of $B R C A 1 / 2$. The primer oligo sequences were listed in Additional file 1: Table S1 and Additional file 2: Table S2. In the second phase of the project, in order to achieve high-throughput and cost-effective sequencing, we designed a NGS panel by adopting the NEBNext Direct sequencing technology developed by New England Biolabs (Ipswich, MA). The panel contains BRCA1/2 genes as well as other 96 known cancer risk-associated genes. We performed panel NGS on all of the 133 Sanger cases along with 85 new cases newly collected. Individually prepared libraries were pooled for Hiseq X sequencing (Illumina, CA, USA) to achieve a minimum 500x mean coverage for the included panel genes. Raw FASTQ data run through in house bioinformatic pipeline with variant calling generated for $B R C A 1 / 2$ genes. Variant filtering and final interpretation were conducted by following the ACMG Standards and Guideline for the Interpretation of Sequence Variants [18] and based on a set of criteria such as allele frequency as well as information from clinical genome databases including ClinVar (https://www.ncbi.nlm.nih.gov/clinvar/), Online Mendelian Inheritance in Man (OMIM) (http://www.omim. org/) and Human Gene and Mutation Database (HGMD) (http://www.hgmd.cf.ac.uk/ac/index.php).

\section{LGRs analysis}

BRCA1/2 LGRs was screened by (Multiplex ligation dependent probe assay) MLPA assay using the SALSA P002 kit and P045 kit for BRCA1 and BRCA2 genes, respectively (MRC-Holland, Amsterdam, the Netherlands). The MLPA reactions were performed according to the manufacturer's instruction. Five normal control samples were included as reference within each MLPA run. Fragment analysis of the PCR products were performed 
Table 1 Small pathogenic variants of BRCA1 and BRCA2 in 218 familial breast and/or ovarian cancer patients

\begin{tabular}{|c|c|c|c|c|c|c|c|c|}
\hline Gene & Mutation & AA change & ClinVar & $\begin{array}{l}\text { No. of } \\
\text { patient }\end{array}$ & $\begin{array}{l}\text { Tumor type } \\
\text { (age Dx) }\end{array}$ & $\mathrm{IHC}$ of $\mathrm{BC}$ & $\begin{array}{l}\text { History of BC } \\
\text { and } O C \text { (age Dx) }\end{array}$ & $\begin{array}{l}\text { Other cancers } \\
\text { in the family } \\
\text { (age Dx) }\end{array}$ \\
\hline \multirow[t]{26}{*}{ BRCA1 } & $c .223 G>T$ & p.Glu75Ter & No & 1 & IDC (R 44, L 54) & ER-/PR-/HER2- & $\mathrm{SOC}(52)$ & $\begin{array}{l}\text { PA EC, PA LC, } \\
M U \text { GC }\end{array}$ \\
\hline & c.1209delT & p.Glu404Asnfs & No & 1 & IDC (47), OC, TC & $\mathrm{ER}+/ \mathrm{PR}+/ \mathrm{HER} 2-$ & $\begin{array}{l}\text { M OC(52), } \\
\text { MA OC(54) }\end{array}$ & \\
\hline & c. $1465 G>T$ & p.Glu489Ter & Yes & 1 & IDC (51) & ER-/PR-/HER2- & $\begin{array}{l}\mathrm{SOC}(52) \\
\text { and } \mathrm{BC}(58)\end{array}$ & \\
\hline & c.1945G > T & p.Glu649Ter & Yes & 1 & IDC (36) & ER-/PR-/HER2- & M BC(58) & \\
\hline & \multirow[t]{2}{*}{ c.2110_2111delAA } & \multirow[t]{2}{*}{ p.Asn704Cysfs } & \multirow[t]{2}{*}{ Yes } & \multirow[t]{2}{*}{2} & IDC (55) & ER-/PR-/HER2- & M BC(57) & \\
\hline & & & & & IDC (68) & ER-/PR-/HER2- & S OC, D OC(40) & \\
\hline & c.3266delA & p.Leu1089Cysfs & Yes & 1 & IDC (62) & ER-/PR-/HER2- & S OC(45) & S LC(65), \\
\hline & c.3295delC & p.Pro1099Leufs0 & No & 1 & IDC (29) & ER-/PR-/HER2- & SBC(40) & \\
\hline & \multirow[t]{2}{*}{ c.3780_3781delAG } & \multirow[t]{2}{*}{ p.Leu1260Phefs } & \multirow[t]{2}{*}{ No } & \multirow[t]{2}{*}{2} & OC (57) & ND & M BC(58) & S GbC(70) \\
\hline & & & & & IDC (39), OC (44) & NA & $\begin{array}{l}\text { MA BC(42), } \\
\text { MA BC(33) }\end{array}$ & \\
\hline & c.4063_4066delAATC & p.Asn1355Lysfs & No & 1 & IDC (40) & $\mathrm{ER}+/ \mathrm{PR}+/ \mathrm{HER} 2-$ & M BC(46) & \\
\hline & \multirow[t]{2}{*}{ c.4065_4068delTCAA } & \multirow[t]{2}{*}{ p.Asn1355Lysfs } & \multirow[t]{2}{*}{ Yes } & \multirow[t]{2}{*}{2} & IDC (38), OC (45) & ER-/PR-/HER2- & M BC (69) & MA EC \\
\hline & & & & & IDC (50) & ER-/PR-/HER2- & $S B C$ & P GC \\
\hline & \multirow[t]{2}{*}{ c. $5154 \mathrm{G}>\mathrm{A}$} & \multirow[t]{2}{*}{ p.Trp1718Ter } & \multirow[t]{2}{*}{ Yes } & \multirow[t]{2}{*}{2} & IDC(35) & ER-/PR-/HER2- & SBC(40) & F BT \\
\hline & & & & & IDC (41) & ER-/PR-/HER2- & SBC(45) & $\begin{array}{l}\text { M EC(69), } \\
\text { MARC }\end{array}$ \\
\hline & c. $5161 C>T$ & p.GIn1721Ter & Yes & 1 & IDC (32) & ER-/PR-/HER2- & $\begin{array}{l}\text { SBC(L 35, R 37), } \\
\text { M OC(47) }\end{array}$ & \\
\hline & c.5173insA & p.Glu1725Argfs & Yes & 1 & IDC (42) & ER-/PR-/HER2- & $\begin{array}{l}\text { S BC(48), } \\
\text { MA BC(48) }\end{array}$ & M LC(51) \\
\hline & c. $5251 C>T$ & p.Arg1751Ter & Yes & 1 & IDC (47) & ND & S DCIS(57) & \\
\hline & $c .5467+1 G>A$ & - & Yes & 1 & IDC (31) & $\mathrm{ER}+/ \mathrm{PR}+/ \mathrm{HER} 2+$ & $\begin{array}{l}\text { SBC(41), SBC(45), } \\
\text { MA BC(51) }\end{array}$ & \\
\hline & \multirow[t]{2}{*}{$\begin{array}{l}\text { c.5468-1_5474del } \\
\text { GCAATTGG }\end{array}$} & \multirow[t]{2}{*}{-} & \multirow[t]{2}{*}{ No } & \multirow[t]{2}{*}{2} & IDC (41) & ER-/PR-/HER2- & S BC(52), S OC(47) & $\begin{array}{l}\text { M EC(77), } \\
\text { F LuC(81) }\end{array}$ \\
\hline & & & & & IDC (36) & ER-/PR-/HER2- & $\begin{array}{l}\text { SBC(L 38, R 44), } \\
\text { MA BC(48) }\end{array}$ & MA EC(50) \\
\hline & \multirow[t]{5}{*}{$\begin{array}{l}\text { C.5470_5477del } \\
\text { ATTGGGCA }\end{array}$} & \multirow[t]{5}{*}{ p.lle1824Aspfs } & \multirow[t]{5}{*}{ Yes } & \multirow[t]{5}{*}{5} & IDC (36) & ER-/PR-/HER2- & SBC (L 37, R 39) & \\
\hline & & & & & IDC (40) & ER-/PR-/HER2- & M BC(44) & \\
\hline & & & & & IDC (58) & ER-/PR-/HER2- & $\begin{array}{l}\text { M OC(55), } \\
\text { MA BC(56) }\end{array}$ & \\
\hline & & & & & $\begin{array}{l}\text { IDC (L 22, R 33), } \\
\text { TC (22) }\end{array}$ & ER-/PR-/HER2- & $\begin{array}{l}\text { M BC(47), } \\
\text { MGM BC(49), } \\
\text { MA BC(33), } \\
\text { MA OC(42) }\end{array}$ & MA RC(47) \\
\hline & & & & & IDC (49) & ER-/PR-/HER2- & SBC(52), PA BC & \\
\hline \multirow[t]{6}{*}{ BRCA2 } & c.-39-1_-39delGA & - & Yes & 1 & IDC (46) & $\mathrm{ER}+/ \mathrm{PR}+/ \mathrm{HER} 2+$ & S BC(48) & \\
\hline & c.469_473delAAGTC & p.Lys157Serfs & No & 1 & IDC (46) & ER-/PR+/HER2- & S BC(L 47, R 49) & $\begin{array}{l}S C C(50), F \operatorname{EsC}(51), \\
B \operatorname{EsC}(64)\end{array}$ \\
\hline & c.470_474del AGTCA & p.Lys157Serfs & Yes & 1 & ILC (31) & $\mathrm{ER}+/ \mathrm{PR}+/ \mathrm{HER} 2-$ & M BC(58) & \\
\hline & c.755_758delACAG & p.Asp252Valfs & Yes & 1 & IDC (48) & $\mathrm{ER}+/ \mathrm{PR}+/ \mathrm{HER} 2-$ & M OC(68) & \\
\hline & c.784delG & p.Ala262Glnfs & No & 1 & IDC (43) & $\mathrm{ER}+/ \mathrm{PR}+/ \mathrm{HER} 2-$ & $\begin{array}{l}\text { SBC(43), } \\
\text { PA BC(50) }\end{array}$ & $\begin{array}{l}F \operatorname{EsC}(57) \\
\text { FU PC(56) }\end{array}$ \\
\hline & C.3109C $>T$ & p.GIn1037Ter & Yes & 2 & IDC (L 39, R 47) & $\mathrm{ER}+/ \mathrm{PR}+/ \mathrm{HER} 2-$ & M BC (39) & \\
\hline
\end{tabular}


Table 1 Small pathogenic variants of BRCA1 and BRCA2 in 218 familial breast and/or ovarian cancer patients (Continued)

\begin{tabular}{|c|c|c|c|c|c|c|c|c|}
\hline Gene & Mutation & AA change & ClinVar & $\begin{array}{l}\text { No. of } \\
\text { patient }\end{array}$ & $\begin{array}{l}\text { Tumor type } \\
\text { (age Dx) }\end{array}$ & $\mathrm{IHC}$ of $\mathrm{BC}$ & $\begin{array}{l}\text { History of BC } \\
\text { and OC (age Dx) }\end{array}$ & $\begin{array}{l}\text { Other cancers } \\
\text { in the family } \\
\text { (age Dx) }\end{array}$ \\
\hline & & & & & IDC (34) & $\mathrm{ER}+/ \mathrm{PR}+/ \mathrm{HER} 2-$ & $\mathrm{PA} \mathrm{BC}(51)$ & $\begin{array}{l}\text { PA GC(70), } \\
\text { PU EsC (59) }\end{array}$ \\
\hline & c.3189_3192delGTCA & p.Ser1064Leufs & Yes & 1 & IDC (55) & $\mathrm{ER}+/ \mathrm{PR}+/ \mathrm{HER} 2-$ & $\mathrm{SBC}(55)$ & \\
\hline & c.3596_3599delACTG & p.Asp1199Valfs & Yes & 1 & IDC (44) & NA & $\begin{array}{l}\mathrm{SBC}(46) \\
\mathrm{MBC}(60)\end{array}$ & \\
\hline & c.4487delC & p.Pro1496GInfs & No & 1 & IDC (37) & $\mathrm{ER}-/ \mathrm{PR}+/ \mathrm{HER} 2-$ & $\begin{array}{l}\mathrm{SBC}(47) \\
\mathrm{MSBC}(41)\end{array}$ & $\begin{array}{l}\text { MA TC(51), MA } \\
\text { TC(55), MS TC(36) }\end{array}$ \\
\hline & c.5495delC & p.Ser1832Leufs & No & 1 & IDC (41) & ER-/PR+/HER2- & S BC(43) & \\
\hline & \multirow[t]{4}{*}{ c. $5682 C>G$} & p.Tyr1894Ter & Yes & 4 & ILC (32) & $\mathrm{ER}+/ \mathrm{PR}+/ \mathrm{HER} 2-$ & $\begin{array}{l}\text { PA BC(45), } \\
\text { PA BC(R 42, L 46) }\end{array}$ & \\
\hline & & & & & MBC (42) & NA & PGF BC(66) & \\
\hline & & & & & ILC (68) & $\mathrm{ER}+/ \mathrm{PR}+/ \mathrm{HER} 2-$ & PA BC(60) & \\
\hline & & & & & ILC (61) & $\mathrm{ER}+/ \mathrm{PR}+/ \mathrm{HER} 2-$ & $S B C(51)$ & \\
\hline & c. $6141 \mathrm{~T}>\mathrm{A}$ & p.Tyr2047Ter & No & 1 & IDC (35) & NA & $\begin{array}{l}\text { S BC(39), MGM } \\
\text { BC(61), MS BC(50) }\end{array}$ & $\begin{array}{l}\text { S LuC (52), } \\
\text { MU LC(66) }\end{array}$ \\
\hline & c. $6359 C>G$ & p.Ser2120Ter & Yes & 1 & $\begin{array}{l}\text { ILC (R 36, L 51), } \\
\text { EC (55) }\end{array}$ & $\mathrm{ER}+/ \mathrm{PR}+/ \mathrm{HER} 2-$ & $\begin{array}{l}M O C(76) \\
M A B C(70)\end{array}$ & \\
\hline & $\mathrm{C} .7588 \mathrm{C}>\mathrm{T}$ & p.GIn2530Ter & No & 1 & IDC (43) & $\mathrm{ER}+/ \mathrm{PR}+/ \mathrm{HER} 2+$ & M BC(63) & \\
\hline
\end{tabular}

$A A$ amino acid, $D x$ diagnosis, IHC immunohistochemistry, IDC invasive ductal carcinoma, $I L C$ invasive lobular carcinoma, $M B C$ medullary breast carcinoma, $L$ left, $R$ right, $B C$ breast cancer, $O C$ ovarian cancer, $L C$ liver cancer, $E C$ endometrial carcinoma, $L U C$ lung cancer, $B T$ brain tumor, $R C$ rectal cancer, $D C I S$ ductal carcinoma in situ, GbC Gallbladder cancer, GC gastric cancer, TC thyroid cancer, CC Colon cancer, EsC Esophagus cancer, PA prostate cancer, $M$ mother, $S$ sister, MS maternal sister, $P A$ paternal aunt, $M G M$ maternal grandmother, $F$ father, $M U$ maternal uncle, $F U$ father uncle, $M A$ maternal aunt, $D$ daughter, $P G F$ paternal grandfather, $B$ brother, $P U$ paternal uncle, ND not done, NA not available

on an ABI 3130xl Genetic Analyzer (Applied Biosystems, Foster City, CA). The data was analyzed by using the Coffalyser software v.9 (Applied Biosystems, Foster City, CA). All of the peak heights were normalized, and the ratio value between $0.7-1.3$ was considered as normal. A ratio value $\leq 0.7$ or $\geq 1.3$ was threshold suggestive of a deletion or duplication, respectively. All patients with a value $\leq 0.7$ or $\geq 1.3$ were confirmed by independent experiments.

Two primer oligos were designed to validate $B R C A 1$ Exon 5-7 duplication. The forward primer sequence was CCGTGCCAAAAGACTTCTACA (Exon 7) and the reverse primer sequence was TTGCTTCCAACCTAGCATCA (Exon 5). Long range PCR amplification was performed with Takara LA Taq DNA polymerase (Takara Bio, USA) by following the manufacturer's manual. The amplified product was run on $0.8 \%$ Agrose gel electrophoresis with EB (i.e. ethidium bromide) and visualized under UV light. The purified amplicons were subjected to Sanger sequencing to confirm amplification fidelity.

\section{Results}

Small pathogenic variants in BRCA1/2 genes

Overall, we identified a total of $31 B R C A 1$ or $B R C A 2$ pathogenic SNVs and Indels in 44 unrelated patients by combining Sanger sequencing and the 98-gene panel NGS assay. Table 1 lists all these small variants. In summary, nearly $59 \%$ (26 of 44 ) of patients had $B R C A 1$ pathogenic variants, and $41 \%$ (18 of 44 ) had BRCA2 pathogenic variants. Two recurrent pathogenic variants (c.5154G > A and c.5468-1_5474del GCAATTGG) in $B R C A 1$ were reported as putative founder mutations [19]. In total, frequency of $B R C A 1 / 2$ small pathogenic variants was $20.2 \%(44 / 218)$ in the studied cohort.

\section{Novel LGRs identified in BRCA1}

Among the 174 patients lacking $B R C A 1 / 2$ small pathogenic variants, three unique $B R C A 1$ LGRs were detected in $5(2.9 \%)$ cases by MLPA assay (Fig. 1a, b, c, d). These include one case with exon5-7dup, two cases with exon13-14dup, and two cases with exon1-22del (Table 2). To our knowledge, these three LGRs have not been reported in Chinese HBOC patients. To confirm MLPA results, we validated exon 5-7dup by designing oligo primers surrounding the putative junction. We obtained a clear and strong 6-8Kb PCR amplicon (Fig. 1e), whose sequence identity was confirmed by Sanger sequencing (data not shown) supporting a tandem duplication event. Overall, BRCA1 LGRs accounted for 16.1\% (5/31) of all patients with $B R C A 1$ pathogenic variants. No LGR was identified in BRCA2. Combining small nucleotide variants and LGRs, we obtained a frequency of $22.5 \%$ (49/218) for this cohort, with BRCA1 LGRs accounting for $10.2 \%$ $(5 / 49)$ of all $B R C A 1 / 2$ pathogenic variants. 

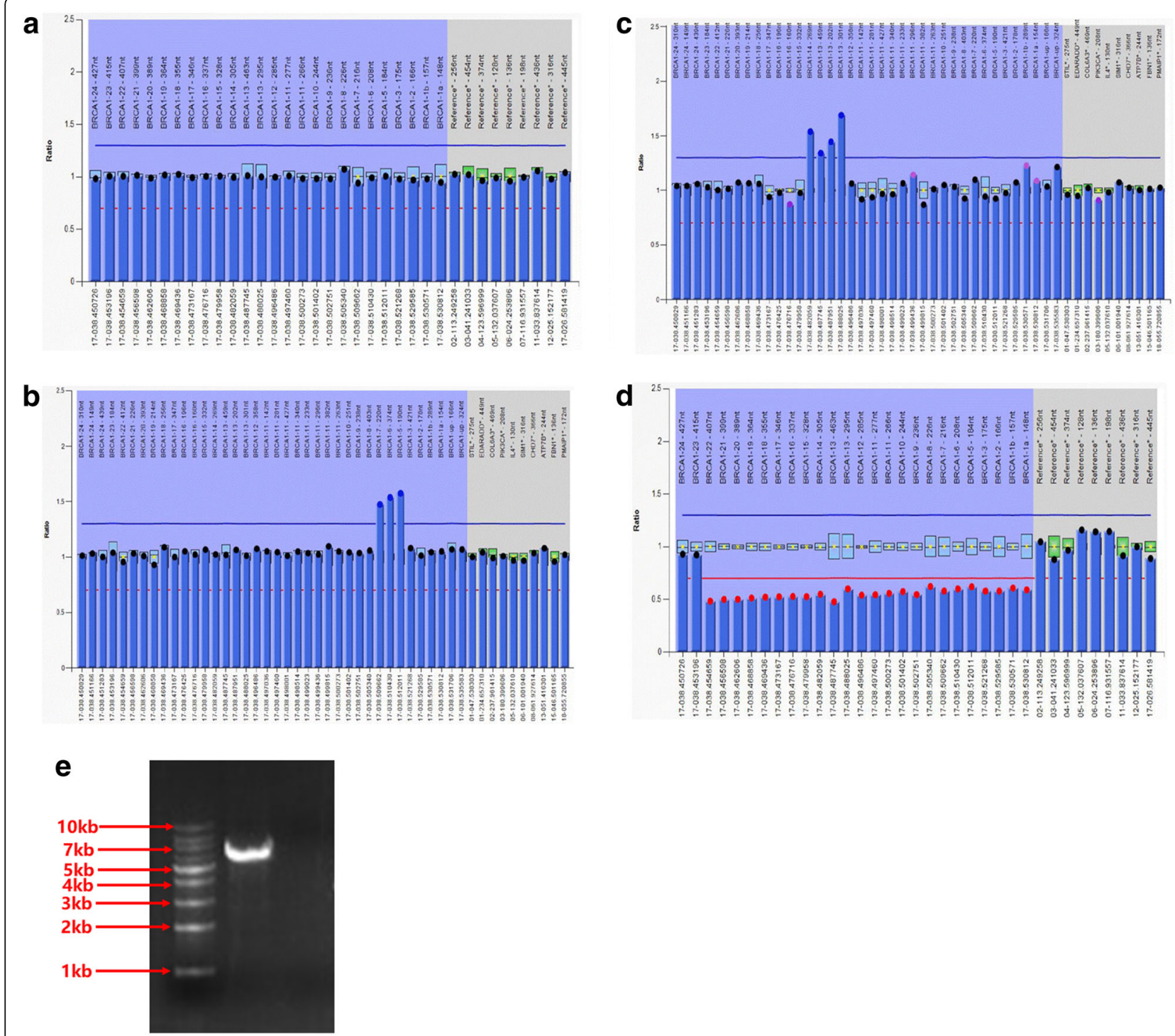

Fig. 1 Three BRCA1 LGRs detected in the HBOC cohort. MLPA result for BRCA1 LGRs in bar chart format generated by Coffalyser software v.9. BRCA1 exons and intra normalized ratio are given on the $X$ axis and $Y$ axis, respectively. Exons having reduced or increased peak ratio are denoted by red or blue dot, respectively. a MLPA result for BRCA1 wildtype. b exon5-7dup. c exon13-14dup. d exon1-22del. e exon5-7dup was confirmed by LR-PCR

Table 2 BRCA1 LGRs in 174 familial breast and/or ovarian cancer patients

\begin{tabular}{|c|c|c|c|c|c|c|c|}
\hline Family ID & Mutation & $\begin{array}{l}\text { Sex of } \\
\text { proband }\end{array}$ & $\begin{array}{l}\text { Phenotype } \\
\text { proband (age Dx) }\end{array}$ & Tumor type & $\mathrm{IHC}$ & $\begin{array}{l}\text { Familial history of breast } \\
\text { cancer and ovarian cancer } \\
\text { (age Dx) }\end{array}$ & $\begin{array}{l}\text { Other cancers in } \\
\text { the family (age Dx) }\end{array}$ \\
\hline 147 & Exon5-7dup & Female & 43 & IDC & ER-/PR-/HER2- & S OC (48) & None \\
\hline 10 & Exon13-14dup & Female & 29 & $\mathrm{MpBC}$ & ER-/PR-/HER2- & M BC(57), PGM BC & None \\
\hline 213 & Exon13-14dup & female & 33 & IDC & $\mathrm{ER}+/ \mathrm{PR}-/ \mathrm{HER} 2-$ & $\begin{array}{l}\text { PA OC(53) and BC(56), } \\
\text { MGM BC (52) }\end{array}$ & None \\
\hline 113 & Exon1-22del & Female & $45(\mathrm{R}), 50(\mathrm{~L})$ & BMC (R), IDC (L) & $\begin{array}{l}\text { R: ER-/PR-/HER2+ } \\
\text { L: NA }\end{array}$ & S BC (42) and OC (45) & $\begin{array}{l}\text { F EC (71), MU } \\
\text { BlaC (71), MB Leu }\end{array}$ \\
\hline 203 & Exon1-24(part)del & Female & 39 & $M B C$ & ER-/PR-/HER2- & M BC (50), MS BC (43) & None \\
\hline
\end{tabular}

LGRs Large genomic rearrangements, $D x$ diagnosis, IHC immunohistochemistry, dup duplication, del deletion, $R$ right, $L$ left, MpBC micropapillary breast cancer, $B M C$ breast mucinous carcinoma, IDC invasive ductal carcinoma, $M B C$ medullary breast carcinoma, $B C$ breast cancer, $O C$ ovarian cancer, $E C$ esophageal carcinoma, BlaC bladder carcinoma, Leu leukemia, $M$ mother, $P G M$ paternal grandmother, $S$ sister, MS maternal sister, $P A$ paternal aunt, $M G M$ maternal grandmother, $F$ father, $M U$ maternal uncle, $M B$ maternal brother 
Gao et al. BMC Cancer

(2019) 19:551

Page 6 of 8

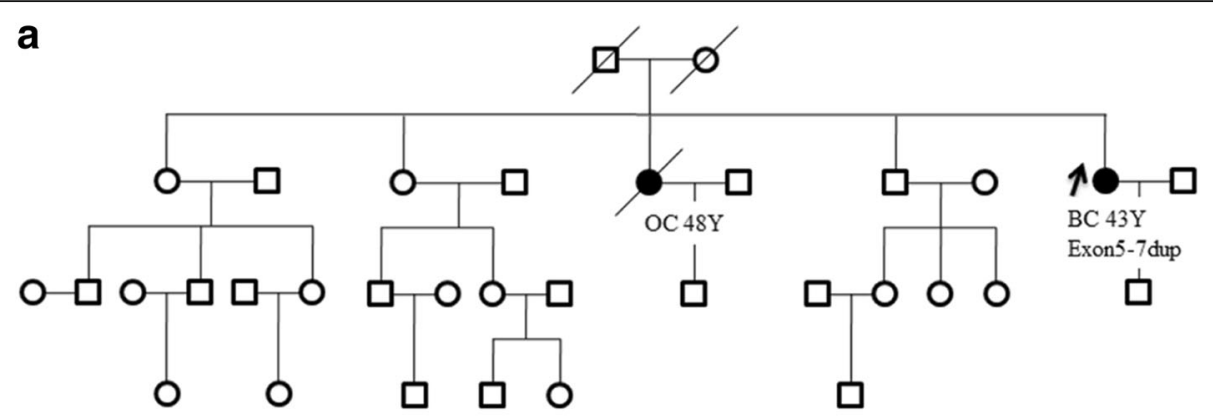

b

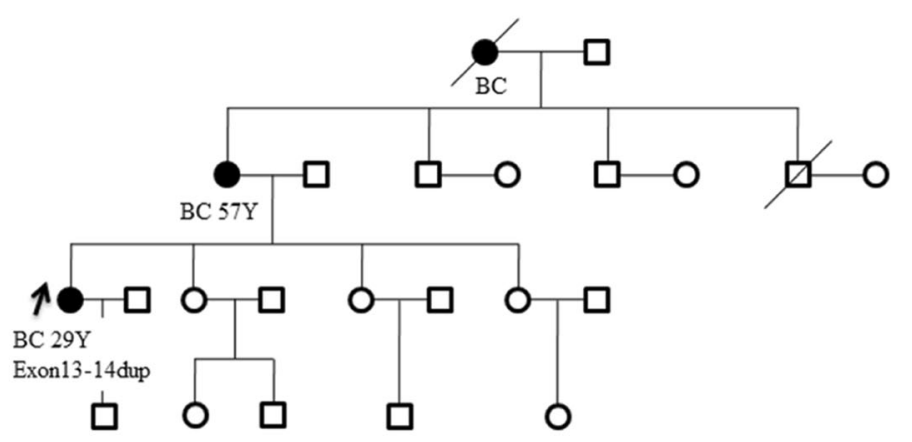

C

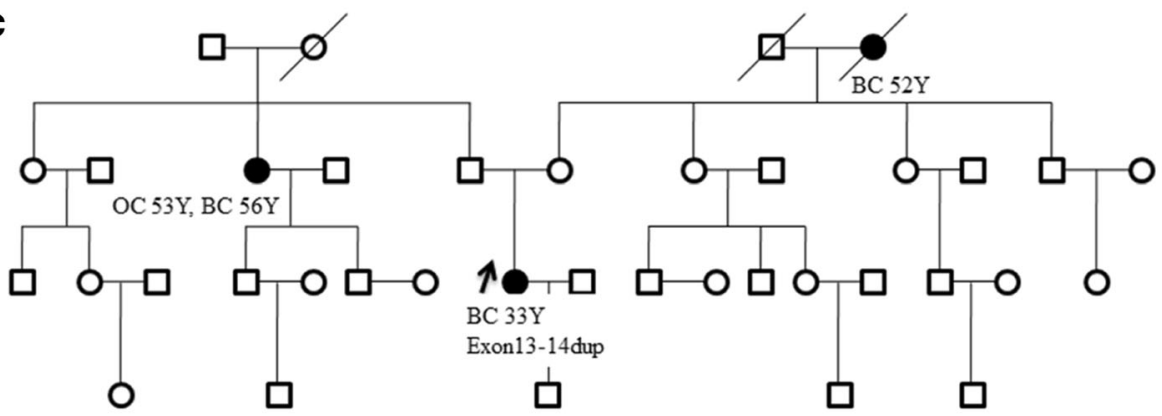

d

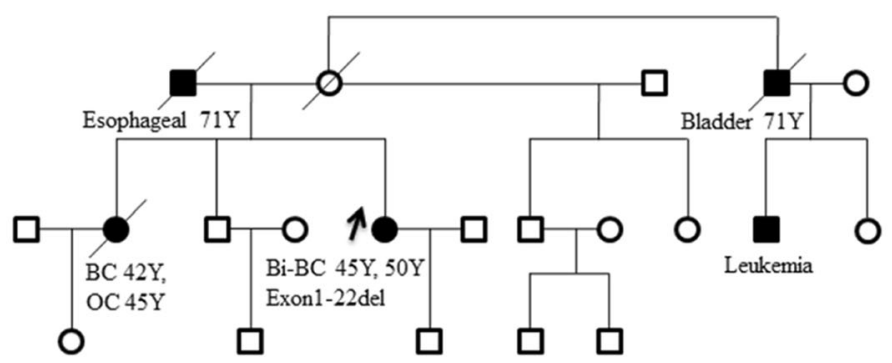

e
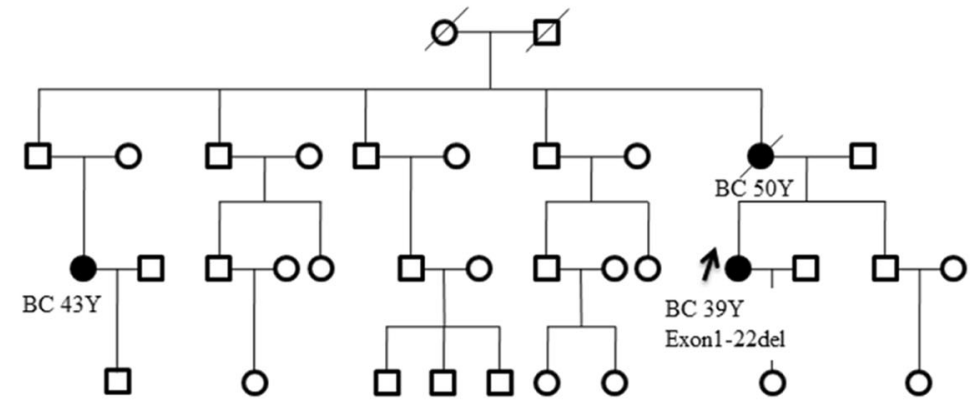

Fig. 2 (See legend on next page.) 
(See figure on previous page.)

Fig. 2 Pedigree of families with proband carrying BRCA1 LGRs. a 147th family with proband carrying exon5-7dup. b 10th family with proband carrying exon13-14dup. c 213th family with proband carrying exon13-14dup. d 113th family with proband carrying exon1-22del. e 203th family with proband carrying exon1-22del. (BC, breast cancer; OC, ovarian cancer; Bi-BC, bilateral breast cancer)

\section{Disease pathology associated with BRCA1 LGRs}

The characteristics and familial cancer history of patients with BRCA1 LGRs were listed in Table 2 and their family pedigrees were shown in Fig. 2. In the five breast cancer patients with BRCA1 LGRs, the most common tumor type was invasive ductal carcinoma. Moreover, Micropapillary carcinoma, mucinous carcinoma as well as medullary carcinoma was found in these patients with BRCA1 LGRs. Although triple negative (ER-/PR -/HER2-) subtype was the most common subtype, luminal subtype (ER+) and HER2-overexpression subtype (ER-/PR-/HER2+) were also exited in patients with BRCA1 LGRs.

\section{Discussion}

In this study, we performed nucleotide sequencing for 218 unrelated FBOC patients living in Eastern China and observed a $20.2 \%$ overall pathogenic variant frequency for BRCA1/2 genes. MLPA assay on the patients lacking small pathogenic variants (174 of 218) further identified 3 unique LCRs in 5 patients, increasing the total $B R C A 1 / 2$ pathogenic variant frequency to $22.5 \%$. All of the three BRCA1 LGRs were not previously reported by Chinese population studies [15-17]. Interestingly, no LGR was identified in BRCA2 gene within our cohort, consistent to the knowledge that LGRs are more frequently observed in $B R C A 1$ than $B R C A 2$. It was revealed that $A l u$-mediated unequal homologous recombination could be the most common mechanism of LGRs found in BRCA1/2, as $72.84 \%$ (59/81) and 52.94\% (9/17) LGRs in BRCA1 and BRCA2 respectively were mediated by this manner [20]. The reason behind higher LGRs frequency in $B R C A 1$ than in $B R C A 2$ might be due to the higher Alu density (41.5\%) in the BRCA1 gene than in the BRCA2 gene [21].

It has been reported that frequency of LGRs ranges from approximately $6-27 \%$ of all detected $B R C A 1$ pathogenic variants, and $B R C A 2$ LGRs play a less role in hereditary breast cancer patients [20]. Thirty five out of three hundreds (12\%) of BRCA1/2-sequencing negative familial breast cancer patients from non-Ashkenazi Jewish in US were found carrying BRCA LCRs, with $10 \%$ (31/300) LCRs detected in BRCA1 and 1\% (4/300) detected in $B R C A 2$, respectively [22]. A nationwide study conducted in South Korea showed that LGRs were detected in $3.7 \%(3 / 81)$ of patients bearing $B R C A 1 / 2$ pathogenic variants and $7.5 \%(3 / 40)$ of patients bearing only BRCA1 pathogenic variants [23]. A large sample screening of high-risk breast cancer patients from Hong
Kong showed that LGRs accounted for $6.67 \%(8 / 120)$ of all $B R C A 1 / 2$ pathogenic variants, involving $8.77 \%(5 / 57)$ of $B R C A 1$ and $4.76 \%(3 / 63)$ of BRCA2, respectively [15]. In our present study, BRCA1 LGRs account for $16.1 \%$ $(5 / 31)$ of all $B R C A 1$ pathogenic variants and $10.2 \%(5 / 49)$ of all $B R C A 1 / 2$ pathogenic variants. For 174 cases with negative sequencing results, five $(2.9 \%)$ were identified with BRCA1 LCRs.

\section{Conclusions}

To conclude, our study has provided evidence that $B R C A 1 / 2$ LGRs contribute significantly to the development of HBOC in Chinese mainland population and LGRs screening should be taken into consideration in hereditary breast cancer consulting. It is imperative that the frequency and spectrum of $B R C A 1 / 2$ should be investigated in the context of both small nucleotide variants and LGRs.

\section{Additional files}

Additional file 1: Table S1. Primers for entire coding exons and intronexon boundaries of BRCA1. (DOCX $30 \mathrm{~kb})$

Additional file 2: Table S2. Primers for entire coding exons and intronexon boundaries of BRCA2. (DOCX $31 \mathrm{~kb}$ )

\section{Abbreviations}

BC: Breast cancer; IHC: Immunohistochemistry; LGRs: Large genomic rearrangements; MAQ: Multiplex amplicon quantification; MLPA: Multiplex ligation dependent probe amplification; NGS: Next generation sequencing; OC: Ovarian cancer; PCR: Polymerase chain reaction

\section{Acknowledgements}

Not applicable.

\section{Authors' contributions}

WMC: designed the study, analyzed the MLPA analysis data and drafted the manuscript. YBZ: performed the analysis of MLPA. YG and ZWP: extracted DNA and performed PCR. XWD, YS, YH and CJL: contributed samples and patient information. GP: reviewed the data and drafted the manuscript. XJW: conceived of the study, participated in its design and coordination and helped to draft the manuscript. All authors read and approved the final manuscript.

\section{Funding}

This research was supported by the grants from National Natural Science Foundation of China (grant number: 81672597), Natural Science Foundation of Zhejiang Province, China (grant number: LY17H160038), Key ResearchDevelopment Program of Zhejiang Province (grant number: 2017C03013, 2019(04001), Science and Technology Program offered by Health Bureau of Zhejiang Province, China (2012RCB006 and 2014KYA006). The funding bodies had no role in study design, collection, analysis, or interpretation of data, or in writing the manuscript.

\section{Availability of data and materials}

The datasets used and/or analyzed during the current study are available from the corresponding author on reasonable request. 


\section{Ethics approval and consent to participate}

This study was approved by the Research and Ethical Committee of Zhejiang Cancer Hospital, China. The written informed consents were obtained from all of the participating patients prior to clinical data and peripheral blood collection.

\section{Consent for publication}

Not applicable.

\section{Competing interests}

The authors declare that they have no competing interests.

\section{Author details}

'Department of Medical Oncology, Zhejiang Cancer Hospital, 1 Banshan East Road, Hangzhou 310022, China. ${ }^{2}$ Institute of Cancer Research, Zhejiang Cancer Hospital, Hangzhou 310022, China. ${ }^{3}$ Department of Breast Cancer Surgery, Zhejiang Cancer Hospital, Hangzhou 310022, China. ${ }^{4}$ Department of Clinical Laboratory, Zhejiang Cancer Hospital, Hangzhou 310022, China. ${ }^{5}$ Department of Clinical Cancer Prevention, the University of Texas, MD Anderson Cancer Center, Houston, TX 77030, USA.

Received: 11 August 2017 Accepted: 29 May 2019

Published online: 07 June 2019

\section{References}

1. Chen W, Zheng R, Baade PD, Zhang S, Zeng H, Bray F, et al. Cancer statistics in China, 2015. CA Cancer J Clin. 2016;66:115-32.

2. Fan L, Strasser-Weippl K, Li JJ, St Louis J, Finkelstein DM, Yu KD, et al. Breast cancer in China. Lancet Oncol. 2014:15:e279-89.

3. Tang NL, Pang CP, Yeo W, Choy KW, Lam PK, Suen M, et al. Prevalence of mutations in the BRCA1 gene among Chinese patients with breast cancer. $J$ Natl Cancer Inst. 1999;91:882-5

4. Cao W, Wang X, Li JC. Hereditary breast cancer in the Han Chinese population. J Epidemiol. 2013;23:75-84.

5. Pang Z, Yao L, Zhang J, Ouyang T, Li J, Wang T, et al. RAD51C germline mutations in Chinese women with familial breast cancer. Breast Cancer Res Treat. 2011;129:1019-20.

6. Sun J, Wang $Y$, Xia $Y, X u Y$, Ouyang $T$, Li J, et al. Mutations in RECQL gene are associated with predisposition to breast Cancer. PLoS Genet. 2015;11:e1005228.

7. Sun J, Meng H, Yao L, Lv M, Bai J, Zhang J, et al. Germline mutations in Cancer susceptibility genes in a large series of unselected breast Cancer patients. Clin Cancer Res. 2017;23:6113-9.

8. Lang GT, Shi JX, Hu X, Zhang CH, Shan L, Song CG, et al. The spectrum of BRCA mutations and characteristics of BRCA-associated breast cancers in China: screening of 2,991 patients and 1,043 controls by next-generation sequencing. Int J Cancer. 2017;141:129-42.

9. Li J, Jing $\mathrm{R}$, Wei $\mathrm{H}$, Wang M, Qi X, Liu H, et al. Germline mutations in 40 cancer susceptibility genes among Chinese patients with high hereditary risk breast cancer. Int J Cancer. 2018. https://doi.org/10.1002/ijc.31601.

10. Puget N, Torchard D, Serova-Sinilnikova OM, Lynch HT, Feunteun J, Lenoir GM, et al. A 1-kb Alu-mediated germ-line deletion removing BRCA1 exon 17. Cancer Res. 1997:57:828-31.

11. Concolino P, Mello E, Minucci A, Santonocito C, Scambia G, Giardina B, et al. Advanced tools for BRCA1/2 mutational screening: comparison between two methods for large genomic rearrangements (LGRs) detection. Clin Chem Lab Med. 2014:52:1119-27.

12. Ruiz De Garibay G, Gutiérrez-Enríquez $\mathrm{S}$, Garre $\mathrm{P}$, Bonache $\mathrm{S}$, Romero A, Palomo L, et al. Characterization of four novel BRCA2 large genomic rearrangements in Spanish breast/ovarian cancer families: review of the literature, and reevaluation of the genetic mechanisms involved in their origin. Breast Cancer Res Treat. 2012;133:273-83,

13. Stadler ZK, Saloustros E, Hansen NA, Schluger AE, Kauff ND, Offit K, et al. Absence of genomic BRCA1 and BRCA2 rearrangements in Ashkenazi breast and ovarian cancer families. Breast Cancer Res Treat. 2010;123:581-5.

14. Palma MD, Domchek SM, Stopfer J, Erlichman J, Siegfried JD, TiggesCardwell J, et al. The relative contribution of point mutations and genomic rearrangements in BRCA1 and BRCA2 in high-risk breast cancer families. Cancer Res. 2008;68:7006-14.
15. Kwong A, Chen J, Shin VY, Ho JCW, Law FBF, Au CH, et al. The importance of analysis of long-range rearrangement of BRCA1 and BRCA2 in genetic diagnosis of familial breast cancer. Cancer Genet. 2015;208:448-54.

16. Lim YK, lau PTC, Ali AB, Lee SC, Wong JE, Putti TC, et al. Identification of novel BRCA large genomic rearrangements in Singapore Asian breast and ovarian patients with cancer. Clin Genet. 2007;71:331-42.

17. Kang P, Mariapun S, Phuah SY, Lim LS, Liu J, Yoon SY, et al. Large BRCA1 and BRCA2 genomic rearrangements in Malaysian high risk breast-ovarian cancer families. Breast Cancer Res Treat. 2010;124:579-84.

18. Richards S, Aziz N, Bale S, Bick D, Das S, Gastier-Foster J, et al. Standards and guidelines for the interpretation of sequence variants: a joint consensus recommendation of the American College of Medical Genetics and Genomics and the Association for Molecular Pathology. Genet Med. 2015;17:405-24.

19. Cao WM, Gao Y, Yang HJ, Xie SN, Ding XW, Pan ZW, et al. Novel germline mutations and unclassified variants of BRCA1 and BRCA2 genes in Chinese women with familial breast/ovarian cancer. BMC Cancer. 2016;16:64.

20. Sluiter MD, Van Rensburg EJ. Large genomic rearrangements of the BRCA1 and BRCA2 genes: review of the literature and report of a novel BRCA1 mutation. Breast Cancer Res Treat. 2011;125:325-49.

21. Ewald IP, Ribeiro PL, Palmero El, Cossio SL, Giugliani R, Ashton-Prolla P. Genomic rearrangements in BRCA1 and BRCA2: a literature review. Genet Mol Biol. 2009:32:437-46

22. Walsh T, Casadei S, Coats KH, Swisher E, Higgins J, Roach KC, et al. Spectrum of mutations in BRCA1, BRCA2, CHEK2, and TP53 in families at high risk of breast cancer. JAMA. 2006;295:1379-88.

23. Seong MW, Cho SI, Kim KH, Chung IY, Kang E, Lee JW, et al. A multiinstitutional study of the prevalence of BRCA1 and BRCA2 large genomic rearrangements in familial breast cancer patients. BMC Cancer. 2014;14:645.

\section{Publisher's Note}

Springer Nature remains neutral with regard to jurisdictional claims in published maps and institutional affiliations.

Ready to submit your research? Choose BMC and benefit from:

- fast, convenient online submission

- thorough peer review by experienced researchers in your field

- rapid publication on acceptance

- support for research data, including large and complex data types

- gold Open Access which fosters wider collaboration and increased citations

- maximum visibility for your research: over $100 \mathrm{M}$ website views per year

At BMC, research is always in progress.

Learn more biomedcentral.com/submissions 